Субтропическое и декоративное садоводство (67)

12. GiveMeBid [Electronic resource]. - Access mode: http://givemebid.com/funduk/

13. Pfisterer J.A. Towards a better understanding of tree failure: investigations into bending stresses of branch junctions and reiterates of European Filbert (Corylus avellana L.) as a model organism // Mitt. Biol. Bundesanst. Land-Forstwirtsch. - Berlin, 2003. - № 394. - P. 125-131.

14. Veriankaite L., Sauliene I., Bukantis A. The modelling of climate change influence on plant flowering shift in Lithuania // Zemdirbyste-Agriculture. - 2010. - Vol. 97. № 1. - P. 41-48. - ISSN: 1392-3196.

\title{
THE SPECIFICS OF PHENOPHASES PASSED BY THE SELECTED HAZEL FORMS IN THE FOOTHILLS OF ADYGEA
}

\author{
Isushcheva T. A., Biganova. S. G., Pchikhachev E. K., Palnikov I. A. \\ Adygei Branch \\ of the Federal State Budgetary Scientific Institution \\ "Russian Research Institute of Floriculture and Subtropical Crops", \\ v.Tsvetochnyy, the Republic of Adygea, Russia, e-mail: tanyaisusheva@mail.ru
}

This paper provides some information about one of the work directions at the Adygei Branch of the FSBSI "Russian Research Institute of Floriculture and Subtropical Crops", located in the foothills of Adygea. It also informs about the number of promising and better forms of common hazel, studied and selected for the period from 2006 to 2018. The information on the site is given to compare and evaluate the best selected forms with the known hazel cultivars grown on the territory of the Adygei Branch. The paper states that the year 2018 was usual in a phenological sense. There is also data about phenological phases of hazel in the Adygei Branch, specifically about the flowering phase of female inflorescences, flowering phase of male inflorescences and the phase of leaves development.

Key words: phenological phases, hazel forms, hazel cultivars, female inflorescences, male inflorescences, leaves.

\section{СОВРЕМЕННЫЕ ДОСТИЖЕНИЯ В ТЕХНОЛОГИИ ПЕРСИКА}

\author{
Цымбалова А. А. \\ Федеральное государственное бюджетное научное учреждение \\ «Всероссийский научно-исследовательский институт иветоводства и субтропических культур», \\ 2. Сочи, Россия, e-mail:n_cimb@mail.ru
}

В статье приводятся последние достижения по технологии выращивания персика. Рассмотрены звенья интенсивной технологии, начиная от сортимента, схем размещения, типов формировок крон, до использования клоновых подвоев селекции Крымской опытно-селекционной станции, как в РФ, так и за рубежом. Приведены результаты исследований комбинаций клоновых подвоев с формировками крон и комбинаций формировок крон со схемами 
Глава 4. Технологии возделывания и методы размножения

размещения деревьев. Система защиты персика от вредителей и болезней на современном этапе включает применение препаратов-фитоактиваторов и феромонных ловушек для снижения пестицидной нагрузки на растения.

Ключевые слова: персик, подвои, схема размещения, сорта, формировки кроны, защита от вредителей и болезней.

Ключевой аспект увеличения урожайности - внедрение новых технологий, в рамках которых одним из наиболее перспективных направлений является совершенствование их элементов, составляющих основу эффективного производства плодов [10]. Сортимент является определяющим звеном при использовании разных технологий выращивания любой сельскохозяйственной культуры.

Для достижения успеха в культивировании персика с применением выращивания по интенсивному типу - наряду с такими важнейшими элементами, как подвой, конструкция насаждения и система обрезки деревьев - необходимо подбирать сорта. В то же время, то, что предлагается по продуктивности, качеству плодов и адаптивности должны быть не ниже лучших районированных сортов [8]. Поэтому во ВНИИЦиСК была продолжена интродукция новых зарубежных сортов персика. Лучшими по качеству плодов, транспортабельности, урожайности по результатам изучения оказались следующие: 'Мадлен Пуйе', 'Харбинджер', 'Редвин', 'Майнред', 'Старк Эрли Глоу 1' и 'Старк Эрли Глоу 2', 'Бэбиголд-5', 'Восток-3'. [26]. Среди сверхранних сортов выделен перспективный сорт 'Спринголд', созревающий во 2-3 декаде июня [21].

В условиях влажных субтропиков Краснодарского края в отличие от других районов появляется лимитирующий фактор - сумма пониженных положительных температур в период покоя персика [20]. За последние годы исследований во ВНИИЦиСК выделены наиболее продуктивные интродуцированные сорта: 'Медин ред’, ‘Эрли блоу', 'Саммерсет' и 'Команче' с потребностью в холоде 1200 часов, а также обладающими высокими биохимическими и вкусовыми качествами плодов [24].

В большинстве стран проблему культивирования персика решают за счёт подбора местности с комфортными для этой культуры условиями среды, а где такой возможности нет - подбором и созданием адаптивных сортов [8].

Для создания современного сортимента персика с устойчивостью к стрессовым и биотическим факторам во ВНИИЦиСК проводится селекционная работа. Коллекция косточковых, котороя насчитывает 58 сортообразцов персика, 8 из них - селекции института (сорт 'Лариса', 2 подвоя - 'Сочинский 7', 'Сочинский 17A' и 5 кандидатов 
в сорта) $[19,25]$. Для расширения сроков созревания непревзойденного сорта 'Редхавен' и сорта 'Коллинс' методом клоновой селекции получены однотипные плоды в течение 25.. 30 дней. Выделенный клон 'Ранняя заря' созревает на 5 дней раньше исходного 'Старк эрли глоу' и на 15 дней раньше сорта 'Редхавен'. Клон сорта 'Коллинс' - 'Николай I' созревает на 5-6 дней раньше исходного сорта, обеспечивая продолжительное поступления плодов в течение летнего периода [18, 23].

На Крымской опытной станции СКЗНИИСиВ созданы сорта персика - 'Скиф', 'Бархатный сезон', которые районированы по Северо-Кавказскому региону [9]. В настоящее время для селекционных программ персика в России в качестве доноров зимостойкости представляют несомненный интерес кубанские сорта - 'Память Симиренко', 'Стойкий', 'Ранний Кубани', ‘Бархатный сезон', ‘Осенний Румянец', нектарины 'Краснодарец' и 'Скифянин'. Из числа новых интродуцированных сортов персика отмечаются 'Андрос', 'Лебедев', 'Рилайнс' и нектарины 'Розовая принцесса', ‘Лола' и 'Обильный' [8].

Необходимость пересмотра сортимента персика вызывается также изменением потребительского спроса на качество продукции: вместо «жёлтомясых» сортов усилился спрос на «беломясые», видимо, связанный с угрозой аллергических заболеваний на жёлтые и красные сорта. Актуальной остается проблема повышения устойчивости к грибным заболеваниям. В результате проведённой во ВНИИЦиСК работы выделена местная форма персика, которая устойчива к грибковым болезням и имеет «беломясые» плоды хорошего качества. Достаточной устойчивостью к курчавости листьев отличались сорта 'Мадлен Пуйе', 'А. Чехов', 'Славный' (форма), 'Амсден'. Особое место занимает генотип сорта 'Лоадел', отличающийся хрящеватостью мякоти, что отвечает требованиям как для консервирования, так и употребления в свежем виде. В группе поздних сортов качеством хрящеватой мякоти обладает генотип сорта 'Бэбиголд', который имеет хорошие вкусовые качества и в свежем виде. [26]. В ходе биохимических исследований установлено, что наилучшими вкусовыми качествами отличались плоды персика сортов: 'Лариса', 'Медин ред’, ‘Эрли блоу', ‘Память Гришко', ‘Эрли ред’ с сахарокислотным индеком в среднем по опыту от 14 отн. ед. и более. В плодах персика сортов: ‘Эрли блоу', 'Память Гришко', 'Медин ред’, 'Славутич' и 'Эрли ред’ высокое содержание акорбиновой кислоты (14,96-23,82 мг/\%) [1].

ВНИИЦиСК методом математического моделирования раскрыто комплексное воздействие абиотических факторов (температуры и влажности воздуха, осадков) на продуктивность сортов персика. Выявлено, 
Глава 4. Технологии возделывания и методы размножения

что урожай сорта 'Редхавен' при улучшении условий увеличивается в 3,2 раза, сорта 'Лариса' - в 2,5 раза, клона 'Красная заря' - в 2,8 раза. Наиболее устойчивый по продуктивности сорт 'Лариса' [4]. Продуктивность сортов персика лимитируют осадки, выпадающие до начала цветения, на большинство сортов оказывает влияние недостаточность тепла во время цветения. Поскольку погодные условия в период цветения не регулируются, то от их колебаний зависит величина урожая, и поэтому фенологическую фазу «начало цветения» можно считать критической [3].

Один из элементов современных технологий производства персиков - использование клоновых подвоев и определенных формировок кроны, позволяющих в наибольшей степени реализовать биологический потенциал культуры по продуктивности и формированию высоких товарных качеств плодов [6]. Распространение новых клоновых подвоев весьма ограничено, в то время, как зарубежный опыт свидетельствует об их широком применении.

В России создана целая серия клоновых подвоев для персика и, в первую очередь, это подвои Крымской ОСС, обладающие устойчивостью к морозам, засухе, корневым нематодам и раку, к переизбытку извести и влаги, отличающиеся слаборослостью в сравнении с традиционными семенными подвоями, снижающие рост привитых растений персика в пределах 40-60 \%.

В Испании и США было проведено изучение клоновых подвоев персика. В их числе испытывались и наиболее перспективные клоновые подвои селекции Крымской ОСС, в частности 'Кубань 86', ВВА-1, ВСВ-1, 'Алаб-1', которые проявили высокую адаптивность к различным экстремальным условиям среды и в настоящее время активно там внедряются [9]. Изученные подвои могут быть использованы в качестве источников устойчивости к различным видам нематод в селекции адаптивных клоновых подвоев нового поколения, т. к. проявляют устойчивость к различным видам нематод [7].

Самый слаборослый подвой ВВА-1 снижает силу роста деревьев на $50 \%$. Он ускоряет созревание плодов, привитых на нём сортов на 7-10 дней, что очень ценно особенно при выращивании ранней продукции [6]. А т. к. срок созревания и уборки плодов каждого сорта составляет всего 5-7 дней, то использование этого подвоя позволит увеличить период поступления свежих плодов персика населению, и снять пики возрастающих объёмов временного хранения и реализации продукции в разрезе одного хозяйства [25]. К сожалению, подвой BВА-1 незасухоустойчив, и в условиях Краснодарского края его применение без полива ограничено [6]. 
В решении проблемы повышения устойчивости деревьев к зимним стрессам большое значение имеют типы формировок, способствующие меньшему повреждению штамбов и крупных скелетных ветвей, а также быстрому восстановлению подмерзших деревьев. Современные типы конструкций садов направлены на уплотнённые схемы посадки [10]. Исследования учёных КубГАУ показали, что за годы наблюдений в пятилетних насаждениях персика сорта 'Память Симиренко' на клоновом подвое BВА-1 с формировкой кроны по типу веретеновидной при схеме посадки 5,0 × 1,5 м урожайность составила 9,6 т/га, при схеме 5,0 × 2,0 м - 8,4 т/га, а при схеме 5,0 × 2,5 м - 7,2 т/га [17].

В опыте Крымской ОСС на подвоях ВВА-1 и ВСВ-1 (слаборослые), 'Эврика 99', ‘Фортуна' и 'Весеннее пламя' (среднерослые) при схеме размещения $5 \times 2$ м и формировке по системе «чаша» выявлено, что по урожайности они не уступают и даже превосходят, особенно по удельной продуктивности, основной подвой (сеянцы персика). Формировки персика сорта 'Майский цветок' при схеме посадки $5 \times 2$ м: гибкое веретено, свободная татура и плоская ромбическая, особенно на подвое BBA-1 позволяют получать в садах интенсивного типа высокий урожай качественных плодов персика [6]. Изучение систем формирования крон и схем размещения деревьев персика в отделении «Крымская опытная станция садоводства» ФГБУН «НБС-ННЦ» на сорте 'Редхавен’ (подвой миндаль, с междурядьем 4,0 м и орошением по бороздам) позволило выделить продуктивные формы кроны, у которых получена урожайность от 19,5 (1 250 дер./га) до 27,0 т/га (1 666 дер./га) - веретеновидная крона, а также в размере 29,0 т/га при плотности посадки 2500 деревьев на 1 га при кустовой кроне [2].

В общем технологическом процессе важное место отводится рациональному размещению культур и сортов. В связи с этим, в СКЗНИИСиВ на основе автоматизированной системы оценки ресурсного потенциала среды построены интегральные карты оптимального размещения персика в зоне Северного Кавказа, позволяющие максимально использовать продуктивный потенциал культур и повысить урожайность насаждений [9].

Исследования Крымского агротехнологического университета показывают, что значительно выше (на 39-43 \%) урожайность опытных насаждений персика сорта 'Редхавен' в условиях предгорного Крыма в возрастном периоде роста и плодоношения 7-8 летних деревьев была отмечена при схеме размещения $5 \times 3$ м при формировании крон по типу свободной пальметты (135,8 ц/га) и усечёно-пирамидальной (136,6 ц/га) в сравнении с контролем - улучшенной вазой $(98,1$ ц/га) [28]. 
Глава 4. Технологии возделывания и методы размножения

Результаты четырёхлетнего опыта ВНИИЦиСК по изучению плодоношения персика в зависимости от плотности посадки и экспозиции склона позволили заключить, что в условиях влажных субтропиков Черноморского побережья России целесообразными для персика сорта 'Редхавен' являются схемы размещения $6 \times 3$ и $6 \times 2$ м (198 ц/га) при формировке по типу «улучшенная чаша» на подвое персик, при схеме $5 \times 2$ м (урожайность 195 ц/га) и V-образной формировке кроны на подвое АП-1, персик можно выращивать на восточных и северных склонах. При размещении $6 \times 1,5$ м урожайность снижается [13].

Кроме того, в нашем институте проводилось сортоизучение персика с уплотнением в ряду $(5 \times 2$ м) c V-образной двухлидерной кроной в сравнении с насаждением $5 \times 3$ м, деревья которого сформированы в виде «улучшенной чаши» с 3-4 скелетными ветвями. Было показано, что сорта 'Коллинс' и 'Спринголд' не проявили себя в уплотнённой посадке. Увеличение урожайности наблюдалось у сорта 'Редхавен' на $18 \%$ - с 106,5 ц/га (при размещении $5 \times 3$ м) до 126,0 ц/га $(5 \times 2$ м) и у сорта 'Ветеран' на 25 \% (с 94,0 ц/га до 118,0 ц/га соответственно). При использовании V-образной формировки высота деревьев не превышала 2,0-2,5 м, что упрощает работу по сбору урожая, проведению опрыскиваний и обрезки [22].

В Италии на равнинных участках у персика доминирует формировка по типу пальметты, высотой до 4 м. Обрезка таких насаждений осуществляется механизировано, а крону «чаша» используют только на склонах. Сады имеют системы орошения. Для защиты плодов от града, сверху над рядами закреплена сетка, которую раскрывают с начала лета до конца уборки урожая [27].

Современное состояние агроэкосистем персика требует новых подходов к защите растений от вредителей и болезней [12]. Усиление пестицидного прессинга на агроценозы, ускорение темпов выработки резистентности у насекомых к инсектицидам и вместе с тем жёсткие требования к снижению остаточных количеств пестицидов в продукции, а также запрещение использования химических средств защиты в рекреационных зонах заставляют активизировать поиск экономичных и безопасных методов борьбы с вредными видами насекомых. В разных странах для снижения численности фитофагов успешно используются феромоны методом дезориентации [30], в т. ч. и в ВНИИЦиСК разработано «Руководство к применению феромонов при защите персика от восточной плодожорки методом дезориентации» [11]. В Китае создана и успешно применяется система феромонных ловушек для мониторинга за персиковой и восточной плодожорками [5]. 
На персике самым опасными и вредоносным заболеванием является курчавость, а из вредителей - восточная плодожорка, поэтому изучение новых препаратов учёными ВНИИЦиСК для защиты персика было направлено в основном на снижение развития этих вредных объектов. Наилучшей системой защиты от курчавости является 3-кратная обработка фунгицидами в период массового развития болезни. Использование препаратов делан, скор, хорус резко снижает развитие этого и других заболеваний персика. В результате санитарно-гигиенического тестирования пестицидов установлено, что скор, байлетон и хорус практически безопасны для окружающей среды [16]. А 2-кратная обработка карбамидом (0,5 \%) в комплексе с фунгицидами (скор 0,1 л/га и хорус 0,15 кг/га) достаточно эффективно сдерживает развитие болезни при средней степени поражения курчавостью листьев. Дополнительное некорневое поступление азота в растения способствует повышению урожайности культуры в среднем на 5,5-8,2 ц/га. Применение карбамида позволяет снизить в системах защиты использование фунгицидов скор и хорус, являющихся более дорогостоящими [14].

Применение в системах защиты персика фитоактиваторов (индукторов иммунитета растений) - иммуноцитофита, агропона, альбита сдерживает развитие курчавости, кластероспориоза и монилиоза; оказывает положительный эффект на биосреды, повышая их устойчивость к негативному воздействию пестицидов. Все биологически активные препараты-фитоактиваторы обладают ростостимулирующими эффектами. Трёхкратное использование в системе защиты персика иммуноцитофита $(0,004$ л/га), помимо снижения вредоносности заболевания, оказывает фитоактивирующее действие, что проявляется в повышении урожайности культуры до 5 ц/га. При трёхкратном применении альбита увеличивается годичный прирост побегов на 10-12 \%. Прибавка урожая на различных сортах персика колеблется от 5 до 8 ц/га [12]. Наиболее эффективные варианты систем защиты персика: альбит в баковой смеси с фунгицидами (делан и скор в половинных нормах расхода), экогель в баковой смеси с фунгицидами, альбит в чистом виде [15].

Приоритетными к применению являются химические средства защиты, интенсивно разлагающиеся в почве и малоопасные для её биотического компонента [29]. Применение в системе защиты персика фастака и дециса экологически приемлемо. Из инсектицидов выраженный негативный эффект на экосистему оказывают препараты старого поколения - золон и дурсбан. Об этом свидетельствует крайне высокий коэффициент экологической нагрузки этих препаратов. 
Глава 4. Технологии возделывания и методы размножения

Практически безопасным для окружающей среды является биологически активный препарат димилин, который обладает специфическим токсическим действием только на вредителей. При появлении тли, бродяжек калифорнийской щитовки рекомендуется применять фитоверм, пиретроиды, феромоны [16]. Пестициды с низкой нормой расхода (пиретроиды, скор и хорус) при однократном их использовании соответствуют адаптивным возможностям агроценоза. Негативное действие пиретроидов проявляется при многократном их применении, а также в насаждениях персика, подвергавшихся многолетнему пестицидному воздействию [29].

Несмотря на высокий и быстрый эффект от применения препаратов старого поколения, замена последних инсектицидами и фунгицидами нового поколения с низкой нормой расхода, феромонами, с использованием фитоактиваторов позволяет снижать затраты на пестициды в 2,2 раза, способствовать охране окружающей среды от загрязнения [12].

Современные условия ведения садоводства предполагают использование новых интенсивных элементов в технологии возделывания плодовых культур, позволяющих перейти от традиционных методов к научно-обоснованному «высокоточному» ведению садоводства с прогнозом фактического состояния насаждений, полного спектра ожидаемых режимов функционирования создаваемого агроценоза, а также повышению эффективности отрасли в целом [9]. Фитосанитарный мониторинг, точная сигнализация с учётом погодных условий, показаний феромонных ловушек, использование экологически безопасных препаратов - основа экологизированной системы защиты персика [16].

Сады косточковых культур нового поколения характеризуются новыми конструкциями насаждений: уплотнённые схемы посадок, сопряжённые с уплощёнными типами формировок крон деревьев; микрозональное размещение культур, сортов, сорто-подвойных комбинаций; оптимизированные системы пищевого и водного режимов; экологизированные системы защиты растений от основных болезней и вредителей, определяющие устойчивость агроценозов, стабильность плодоношения, высокую урожайность и качество плодов.

Совершенствование элементов технологии производства плодов косточковых культур, связанное с изменяющимися погодными условиями и участившимися стрессами, а также с новыми подходами к формированию садовых ценозов, является актуальным направлением научных исследований [10]. 


\section{Библиографический список}

1. Абильфазова Ю.С. Биохимический состав плодов персика под воздействием неблагоприятных погодных условий субтропиков России // Субтропическое и декоративное садоводство. - 2018. - Вып. 65. - С. 142-147. - doi: 10.31360/2225-3068-2018-65-142-147. 2. Бабинцева Н.А. Особенности роста и плодоношения насаждений персика (Prunus persica (L.) Batsch) в зависимости от конструкции сада // Cбор. науч. тр. Государственного Никитского ботанического сада. - 2017. - № 144. - Ч. II. - С. 5-9. - ISSN: 0201-7997.

3. Беседина Т.Д., Смагин Н.Е., Добежина С.В. Оценка влияния агрометеорологических факторов влажных субтропиков России на урожай сортов персика методом математического моделирования [Электронный ресурс] // Политематический сетевой электронный научный журнал Кубанского государственного аграрного университета (Научный журнал КубГАУ), - 2016. - № 121(07). - С. 846-859. - doi: 10.21515/1990-4665-121-049.

4. Беседина Т.Д., Смагин Н.Е., Добежина С.В. Сортоизучение культуры персика для оптимизации размещения во влажных субтропиках России // Субтропическое и декоративное садоводство. - 2017. - Вып. 60. - С. 67-72. - ISSN: 2225-3068.

5. Вендило Н.В., Плетнев В.А., Лебедева К.В. Применение феромонов для защиты плодовых садов от вредных насекомых // Агрохимия. - 2009. - № 8. - С. 72-84. ISSN: 0002-1881.

6. Ерёмин В.Г. Новые технологии возделывания персика в Краснодарском крае // Садоводство и виноградарство. - 2006. - № 6. - С. 7-8. - ISSN: 0235-2591.

7. Ерёмин В.Г. Оценка устойчивости клоновых подвоев персика к абиотическим и биотическим стрессорам [Электронный ресурс] // Политематический сетевой электронный научный журнал Кубанского государственного аграрного университета (Научный журнал КубГАУ). - 2010. - № 62(08). - С. 343-352. - URL: http://ej.kubagro. $\mathrm{ru} / 2010 / 08 / \mathrm{pdf} / 10 . \mathrm{pdf}$

8. Ерёмин В.Г., Ерёмина О.В. Сортимент персика для Краснодарского края [Электронный ресурс] // Современное садоводство. - 2014. - № 2. - С. 2. URL: http://journal.vniispk.ru/pdf/2014/2/16.pdf

9. Заремук Р.Ш. Высокоточная технология производства плодов косточковых культур на Юге России // Мат. междунар. науч.-практ. конф. посвящённой памяти учёного-помолога В.П. Семакина. - Селекцентр по Центрально-Чернозёмным областям; ГНУ Всероссийский научно-исследовательский институт селекции плодовых культур, 2011. - С. 84-89.

10. Заремук Р.Ш. Совершенствование элементов технологии производства плодов косточковых культур в условиях проявления климатических стрессов на Северном Кавказе // Плодоводство и виноградарство Юга России. - 2013. - № 19(1). - С. 38-47. - ISSN: 2219-5335.

11. Игнатова Е.А. Руководство к применению феромонов при защите персика от восточной плодожорки методом дезориентации // Субтропическое и декоративное садоводство. - 2015. - Вып. 52. - С. 95-106. - ISSN: 2225-3068.

12. Карпун Н.Н. Методические положения по применению препаратов нового поколения в системах защиты персика. - Сочи: ВНИИЦиСК, 2013. - 61 с. ISBN: 978-5-904533-18-2.

13. Козин К.В. Рост и плодоношение персика в зависимости от плотности посадки и экспозиции склона во влажных субтропиках России: автореф. дис. ... канд. с.-х. наук. - Краснодар, 2000. - 25 с. 
Глава 4. Технологии возделывания и методы размножения

14. Леонов Н.Н. Эффективность применения карбамида в защите персика от курчавости листьев (Taphfrina deformans Tul.) // Субтропическое и декоративное садоводство. - 2016. - Вып. 57. - С. 79-84. - ISSN: 2225-3068.

15. Михайлова Е.В. Повышение неспецифической устойчивости персика (Prunus persica (L.) Batsch) к фитопатогенам при применении иммуноиндукторов: автореф. дис. ... канд. биол. наук. - М., 2017. - 24 с.

16. Осташёва Н.А., Игнатова Е.А., Янушевская Э.Б., Фогель В.А. Основы биологизированой системы защиты персика от вредных организмов в субтропиках России // Биоресурсы, биотехнологии, экологически безопасное развитие Агропромышленного комплекс: сб. науч. тр. - Сочи: ВНИИЦиСК, 2007. - Вып. 40. - C. 358-370. - ISSN: 2225-3068.

17. Проворченко А.В., Колчева Е.В. Физиологические аспекты роста и плодоношения персика на клоновом подвое ВВА-1 в зависимости от схемы размещения деревьев [Электронный ресурс] // Политематический сетевой электронный научный журнал Кубанского государственного аграрного университета (Научный журнал КубГАУ). 2016. - №121(07). - doi: 10.21515/1990-4665-121-082.

18. Рындин А.В., Смагин Н.Е., Абильфазова Ю.С. Перспективные сорта персика для влажных субтропиков России (Сочи) // Субтропическое и декоративное садоводство. -2011. - Вып. 41. - С. 119-123. - ISSN: 2225-3068.

19. Рындин А.В., Мохно В.С. Генетические ресурсы садовых растений в субтропиках России и возможности их использования // Субтропическое и декоративное садоводство. - 2012. - Вып. 47. - С. 13-22. - ISSN: 2225-3068.

20. Рындин А.В., Драгавцева И.А., Мохно В.С. Соответствие требований культуры персика условиям среды влажных субтропиков России // Садоводство и виноградарство. - 2013. - № 1. - С. 24-29. - ISSN: 0235-2591.

21. Смагин Н.Е. Подбор сортов персика для субтропиков России // Субтропическое и декоративное садоводство. - 2012. - Вып. 47. - С. 77-83. - ISSN: 2225-3068.

22. Смагин Н.Е. Формировка и обрезка персика в уплотнённых насаждениях // Субтропическое и декоративное садоводство. - 2016. - Вып. 59. - С. 164-168. ISSN: 2225-3068.

23. Смагин Н.Е., Абильфазова Ю.С. Характеристика сортов персика для импортозамещения // Вестник российской сельскохозяйственной науки. - 2016. - № 5. - C. 57-59. - ISSN: 2500-2082.

24. Смагин Н.Е., Абильфазова Ю.С. Лучшие по продуктивности и устойчивые к болезням сорта персика для влажных субтропиков г. Сочи // Новые технологии. - 2017. - № 3. - C. 117-125. - ISSN: 2072-0920.

25. Смагин Н.Е., Абильфазова Ю.С. Атлас перспективных сортов персика. - Сочи: ВНИИЦиСК, 2017. - 48 с. - ISBN: 978-5-904533-27-4.

26. Смагин Н.Е., Рындин А.В., Кочкина Ю.С. Геноресурсы персика в субтропиках России // Субтропическое растениеводство и южное садоводство на Черноморском побережье Краснодарского края Российской Федерации: сб. науч. тр. - Сочи, ВНИИЦиСК, 2009. - Вып. 42. - Ч. II. - С. 159-168. - ISSN: 2225-3068. 27 Тутберидзе Ц.В., Гребенюков С.Н., Макоян Н.П. Научные исследования и технологические приёмы современного производства южных плодовых и субтропических культур в Италии (результаты делового визита сотрудников ГНУ ВНИИЦИСК Россельхозакадемии в Centro Ricerche Produzioni Vegetali Italia) // Научные исследования в субтропиках России: сб. трудов молодых учёных, аспирантов и соискателей. - Сочи: ВНИИЦиСК, 2013. - С. 22-29. - ISBN: 978-5-904-533-19-9. 
Субтропическое и декоративное садоводство (67)

28. Щербатко Н.М. Рост и продуктивность персика в зависимости от конструкции крон и насаждений в условиях предгорного Крыма // Научные труды Южного филиала Национального университета биоресурсов и природопользования Украины «Крымский агротехнологический университет». Серия: Сельскохозяйственные науки. - 2011. - № 134. - С. 99-105. - ISBN: 2224-8420.

29. Янушевская Э.Б., Карпун Н.Н. Разработка основ экотоксикологически эффективных технологий возделывания персика // Плодоводство и виноградарство Юга России. - 2011. - № 9. - С. 108-117. - ISSN: 2219-5335.

30. Stelinski L.L., Miller J.R., Ledebuhr R., Siegert P., Gut L.J. Seasonlong mating disruption of Grapholita molesta (Lepidoptera: Tortricidae) by one machine application of pheromone in wax drops (SPLAT\$OFM) // Journal of Pest Science. - 2007. - Vol. 80(2). - P. 109-117.

\section{MODERN ADVANCES IN THE TECHNOLOGY OF PEACH}

Tsymbalova A. A.

Federal State Budgetary Scientific Institution "Russian Research Institute of Floriculture and Subtropical Crops", c. Sochi, Russia, e-mail:n_cimb@mail.ru

The paper presents the latest advances in peach growing technology. It considers the links of intensive technology, ranging from assortment, layouts, types of crown formation, to the use of clonal rootstocks in the selection of the Crimean Experimental-Breeding Station both in Russia and abroad. It also includes the results of studies about combinations of clonal rootstocks with crown formations and combinations of crown formations with tree arrangement schemes. The system of peach protection from pests and diseases at the present stage includes the use of preparations-phytoactivators and pheromone traps to reduce the pesticide load on plants.

Key words: peach, rootstocks, layouts, cultivars, crown formations, protection against pests and diseases. 